\section{Myxoma, Soft Tissue}

Jacqueline E. van der Wal

Department of Pathology, The Netherlands

Cancer Institute/Antoni van Leeuwenhoek

Hospital, Amsterdam, The Netherlands

\section{Cross-References}

- Ectomesenchymal Chondromyxoid Tumor

- Odontogenic Myxoma

\title{
Description
}

A benign soft tissue tumor characterized by bland spindle-shaped cells in an abundant, hypovascular, myxoid, or mucoid stroma. 